\title{
A Case Study of Transient Dyslexia
}

\author{
Ronan G. Reilly \\ Department of Computer Science \\ National University of Ireland, Dublin
}

\section{Running head}

Transient Dyslexia

\section{Mailing address}

Dr Ronan Reilly

Department of Computer Science

National University of Ireland, Dublin

Belfield

Dublin 4

IRELAND 


\title{
A Case Study of Transient Dyslexia
}

\author{
Ronan G. Reilly \\ Department of Computer Science \\ National University of Ireland, Dublin
}

This paper presents a case study of a seizure-induced transient dyslexic episode experienced by a radio presenter while reading a script live on air. An analysis of the recording of the episode in conjunction with the script being read yields a number of interesting observations. There is, for example, a distinct temporal pattern of breakdown from what can be characterised as orthographic errors through to semantic confusions. Many of the orthographic errors can be explained as a form of repetition blindness. Furthermore, the pattern of lexical error lends support to a two-stage model lexicalisation.

\section{Keywords}

Dyslexia, repetition blindness, epileptic seizure, reading 


\title{
A Case Study of Transient Dyslexia
}

\author{
Ronan G. Reilly \\ Department of Computer Science \\ National University of Ireland, Dublin
}

\section{Introduction}

This paper presents an analysis of an episode of transient dyslexia experienced by a male radio presenter (RHR) while making a live broadcast. Because of the nature of the incident, the entire event was taped. It was the view of RHR's neurologist that the source of the episode was a seizure focussed on an injury received some 30 years prior, to the left temporal cortex. From a research point of view, the significance of the episode is that the tape provides an unfolding of an episode of dyslexia over time, something that I believe is unique. In addition, because of the context in which it occurred, we know what RHR was trying to say, and how it came out. It provides an additional perspective to that of lesion-based studies, since this episode gives rise to a range of different error types as it progresses.

\section{Background}

At the time of the incident, RHR was 51 years old. He had received an injury to the left temporal cortex 30 years prior to the incident. At the time this gave rise to five day's post-trauma amnesia and residual right hemiparesis for approximately two weeks. He experienced two seizures 10 years later. These seizures ceased when he was prescribed phenobarbitol. However, leading up to the incident described in this paper, RHR reported being lax in taking the phenobarbitol. It should be noted that RHR is left handed, though right footed.

The incident occurred at the beginning of a radio broadcast. The structure of the broadcast involved RHR reading from a script introducing the topic of the programme, which would then be discussed by commentators in the local studio in Dublin and in regional studios connected by radio link. It was in the middle of reading this script that the dyslexic episode took place. RHR has no memory of the episode and has since made a full recovery. 


\section{<Insert Figure 1 about here>}

\section{An information processing framework}

Before analysing RHR's transcript, it is useful to sketch out a model indicating possible points of disruption in the processing and/or flow of information (see Figure 1). In Figure 1, ovals represent processes, and the rectangles represent either temporary or permanent information stores. The use of an information processing style is a notational convenience and does not represent a commitment to a particular modelling framework. The model is an abstraction of a variety of neuropsychologically motivated models of reading aloud, though specifically of the models of Patterson and Morton (1985) and Lesser and Milroy (1993). A key feature of the model is that it represents three routes (indicated by the shaded ovals) from graphemic representation through to phonological output. Evidence to support these separate routes comes from studies of patients with brain damage. For example, Schwarz, Saffran, and Marin (1980) describe a patient (WLP) who could read both regular and irregular ${ }^{1}$ words aloud but with almost no comprehension (impaired semantic system, but intact non-semantic conversion). Cosslett (1991) described a patient, WT, who could read words with impaired comprehension, but could not read non-words (impaired semantic system and grapheme-to-phoneme conversion). Finally, McCarthy and Warrington (1986) describe a patient with poor comprehension, who made errors in reading aloud irregular words, but who was able to pronounce nonsense words without difficulty (all routes except grapheme-to-phoneme conversion impaired). While these data are suggestive of several separate routes, none of the patients described above represent a "pure" example of one single intact route. Furthermore, the information flow model in Figure 1 while useful as a way of categorising errors, may not be the most illuminating way of representing the dynamics of the reading process. For that, we may need to look to connectionist models to give us a more realistic dynamical account (e.g., Plaut \& Shallice, 1993). Nonetheless, with these caveats in mind, Figure 1 will suffice as useful scaffolding for a discussion of the transcript.

\section{Overview of tape and transcript}

When one listens to the tape at the point where the disruption starts (cf. Table 1), one gets the impression of someone struggling to read bad handwriting. RHR's delivery slows down and 
becomes hesitant. The slowing down is interspersed with bursts of coherent speech, though with many neologisms, lexical intrusions, and what appears to be some syntactic ill-formedness. Many of the hesitations involve corrections and restarts. The tape stops abruptly when the programme producer intervenes to end transmission.

\section{<Insert Table 1 about here>}

Table 1 is a transcript of the relevant part of the tape. The utterances are broken down roughly into intonation units (Chafe, 1994), where each line represents a separate intonation unit in as much as this could be discerned, particularly during the height of the disruption. Each row comprises four columns providing the intonation unit number, timing information, a textual rendition of the utterance, and the original script used by RHR. The errors of interest are indicated in bold.

The first indication that there may be something about to go wrong is the point at Unit 1 in Table 1, where RHR appears initially to use the wrong word-ending, and then proceeds to correct himself, producing something like "a little speedy...er than." This might be classed as a normal slip of the tongue, but one should keep in mind that RHR is an exceptionally fluent presenter, and such a slip would normally be a rare occuRHRence.

The next point of disruption occurs at Unit 4 where RHR has difficulty producing the word "faithful", saying instead "fail...faithful." Thus, soon after the word is spoken, it is rapidly coRHRected (within $143 \mathrm{~ms}$ ). Possible loci of disruption implicated here will be discussed when we take a closer look at specific eRHRors.

By Unit 5 we have the start of the most dramatic phase of the disruption, with neologisms, lexical intrusions, deletions, substitutions, and what initially appears to be a syntactically ill-formed utterance. The scripted phrase "And in a (sic) increasingly secular world" becomes something like "And in a caresingly circul... circular world." The word "increasingly" is rendered as "caresingly", and "secular" as "circular".

Within the same unit, a striking eRHRor occurs where "understand the demands of the future" is rendered as "understands of the future". This looks initially like a syntactic problem, but what seems to have happened here is that there has been a blending of the "understand" and

\footnotetext{
${ }^{1}$ An ability to pronounce words with irregular spelling to sound relationships suggests intact lexical access even though comprehension may be impaired
} 
"demands". Whether this blending occurs at the orthographic or phonological stage in Figure 1 will be discussed later.

As the disruption proceeds there are an increasing number of lexical intrusions, some of which are semantically unrelated to the script text. One example of this is the word "commercially" (Unit 5). A possible explanation for this intrusion (the word does not occur anywhere in the script) is that at some level RHR has realised something is amiss, and the standard procedure when something is going wrong is to go to a commercial break. Alternatively, his producer who communicates with him over headphones, may have been trying to instruct him to go to a commercial break, and his/her instructions intruded into RHR's speech.

\section{Error Analysis}

In attempting to understand what is going on during the episode, one has to deal with a large number of possible points at which the disruption may be occurring. In addition, because the most likely cause of the disruption is a spreading wave of synchronised electrical activity, disruption will probably be occurring at more than one point simultaneously. This makes identifying the provenance of some errors quite difficult. Nonetheless, a reasonably clear picture emerges from the transcript of three broad classes of error: (1) Errors at the orthographic processing stage prior to lexical access, (2) errors in accessing the correct entry in the le xicon, and (3) errors in assembling the phonological representation. A few errors reflect a combination of two or more of these factors. In addition, there appear to be some problems at the phonetic and prosodic levels, dealing with timing and intonation. However, it is difficult in these latter cases to determine whether this is due to the effects of feedback on the speaker, or due to disruption of articulatory motor programs.

\section{Orthographic analysis errors}

It would appear that disruption of the orthographic analysis stage (cf. Figure 1) is the first to occur in the transcript (Unit 1: "speedy er"), and recurs once at the end (Unit 13: "cuvents"). This class of error involves the deletion of letter sequences, particularly when more than one letter of the same type occurs in a word or word pair. Another feature of this type of error is that it also involves the deletion of letters adjacent to the repeated letter or sequence of letters.

One explanation for the letter deletions is that they are an example of orthographic repetition blindness; a phenomenon first identified by Kanwisher (1987) and more recently explored by Harris 
(in press). Orthographic repetition blindness occurs when sequences of words are presented briefly $(\approx 150 \mathrm{~ms})$ in rapid succession in the same visual location on a computer screen. Harris has demonstrated that if a subject sees flesh and crush in rapid succession, they will report seeing flesh and crumb (or a similar second word that preserves the non-repeating letters). What seems to happen is that the first word "steals" the letters that are common to both words. In normal reading, repetition blindness does not occur, but in RHR's case, the disruption caused by the seizure affects his ability to maintain multiple instances of letters of the same type.

While some of the examples listed below could be repetition blindness at the level of phonological representation (Bavelier \& Potter, 1992), the simplest account of this class of errors is to attribute them to problems at the orthographic analysis level.

$\mathrm{SPEEDIER} \Rightarrow \mathrm{SPEEDY}\left(\mathrm{U}_{\mathrm{NIT}} 1\right)$

The inclusion of this error is in the orthographic category is, at least initially, a little debatable. It might be due either to a failure to inflect the retrieved lemma for speed correctly, or to the deletion of one of the multiple instances of the letter " $\mathrm{e}$ ". I believe the latter a more likely explanation given the type of errors in its immediate vicinity, and also that there are no other obvious examples of inflectional errors in the transcript.

\section{FAITHFUL $\Rightarrow$ FAIL $\left(U_{\text {NIT }}^{4}\right)$}

In this example, the second instance of the letter " $\mathrm{f}$ " and the immediately preceding letters appear to get deleted, resulting in an incorrect lexical item being accessed. Again this seems to be best explained as another example of repetition blindness.

$$
\text { INCREASINGLY } \Rightarrow \text { CREASINGLY }(?) \Rightarrow \text { CARESINGLY (UNIT 5) }
$$

The script context is "in a increasingly secular" in which the sequence "in" occurs three times. The most likely account of this error is that the preposition "in" steals the initial letters of "increasingly" leaving "creasingly". This then either undergoes a disruption in letter order, or else there is a disruption at the phonological assembly stage.

$$
\text { UNDERSTAND THE DEMANDS } \Rightarrow \text { UNDERSTANDS (UNIT 5) }
$$

This is one of the more striking examples of duplicate deletion. Here the letter sequence "and" in "understand" plus the initial letters of the following word are deleted, and a blend of the remaining letters is produced. It could be argued that this blending might also have occurred at the 
phonological output stage. However, the proposed cause for the loss of material (i.e., difficulty in maintaining multiple tokens of the same type) is not as compelling an explanation at the phonological

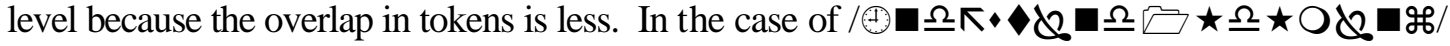
there are two overlapping phonemes $\lambda_{2} \mathbf{\square} /$.

\section{CURRENT EVENTS $\Rightarrow$ CUVENTS $\left(U_{\text {NIT }} 13\right)$}

This seems to be another example of repetition blindness. In this case, the overlapping sequence is "ent". Again, the case could be made that the problematic stage is at the phonological

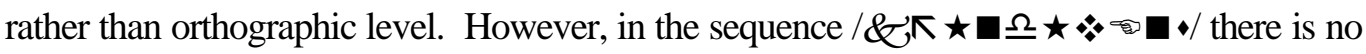
overlapping sub-sequence of phonemes. Therefore, the more likely locus of disruption is at the orthographic level.

\section{Semantic system errors}

The semantic errors comprise two types of paralexias: semantic (e.g., father for bishop) and visual (e.g., circular for secular), the generation of neologisms (e.g., commersk for comment), and unrelated intrusions. The general trend in the transcript is for the semantic errors to appear in the latter half of the transcript. Many of the errors in this category are characteristic of patients with deep dyslexia (Marshall \& Newcombe, 1980). This is an acquired dyslexia in which patients tend to produce reading errors that involve words that are semantically related to the printed word, such as reading sister for daughter.

\section{SECULAR $\Rightarrow$ CIRCULAR (UNIT 5)}

This is arguably a visual paralexia, given the orthographic similarity between the two words. On the other hand, the scripted phrase "secular world" and the utterance "circular world" are both semantically plausible, so there may also be a semantic dimension to the error given the possible association between the concepts circular and world.

\section{$\varnothing \Rightarrow$ COMMERCIALLY (UNIT 5)}

This word is an example of an unrelated intrusion. It is neither in the script nor is it semantically related to the script content. Nonetheless, it does bear a semantic relationship to the broader context of the radio broadcast. As discussed earlier, it is quite likely that, aware of the difficulty he was having, RHR considered taking a commercial break or was being prompted to do so by his producer. 


\section{$\mathrm{B}_{\text {ISHOP }} \Rightarrow \mathrm{F}_{\text {ATHER }}\left(\mathrm{U}_{\mathrm{NIT}} 6\right)$}

This is a classic semantic paralexia in which the word bishop is replaced with the more frequent form of address for priests: Father.

\section{$\mathrm{B}_{\mathrm{ISHOP}} \Rightarrow$ PARISH $\left(\mathrm{U}_{\mathrm{NIT}} 7\right)$}

This appears to be a combination of visual and semantic paralexia. There is a considerable overlap in letters (four out of six) between bishop and parish. There is also the obvious semantic connection.

$$
\text { JOINS } \Rightarrow \text { DISTORES (UNIT 10) }
$$

This is the first example of a neologism in the script. It occurs after the semantic paralexias and probably represents a progressive deterioration of the semantic system as a result of the seizure activity. It bears no obvious visual or semantic relationship to the text. Note, however, that it is appropriately marked for number given its syntactic context.

COMMENT $\Rightarrow$ COMMERSK (UNIT 10)

This is another of the neologisms occurring in Unit 10 but one that does bear some resemblance to the script.

$$
\text { CONVERSATION } \Rightarrow \text { COMMESTICATION (UNIT 10) }
$$

Another example of a neologism that is properly inflected for syntactic context.

$$
\mathrm{ABOUT} \Rightarrow \text { WITH (UNIT } 11 \& 12)
$$

This the only example of the substitution of one function word for another, a phenomenon which has been observed in patients classified as suffering from deep dyslexia (Morton \& Patterson, 1980).

\section{$\mathrm{C}_{\text {HALLENGING }} \Rightarrow$ COMMER $\left(\mathrm{U}_{\text {NIT }} 12\right)$}

This is possibly another example of an interference from the word commercially that intruded earlier.

$$
\mathrm{J}_{\mathrm{ESUIT}} \Rightarrow \mathrm{C}_{\text {HRISTOMER }}\left(\mathrm{U}_{\mathrm{NIT}} 14\right)
$$

This appears to be a mixture of neologism and semantic paralexia. The root of Jesuit, Jesus, seems to have been replaced by its close semantic associate Christ, and then distorted, producing a 
neologism that looks rather like the name Christopher, though this name does not occur anywhere in the script.

JESUIT $\Rightarrow$ JESSIMET (UNIT 15)

A neologism that bears some orthographic similarity to the scripted word.

\section{Phonological system errors}

It was difficult to identify "pure" phonological errors. The more obvious ones tended to occur in combination with semantic system errors (see below).

\section{THOMAS $\Rightarrow$ TOMLIS $\left(\mathrm{UNIT}_{\text {N }}\right.$ )}

It's not entirely clear what has happened here. There is a brief hesitation between tom and lis that suggests perhaps some problems with the phonological output system. An alternative explanation is that the problem has arisen earlier in the processing stream, perhaps at the orthographic level. However, in the earlier cases in which orthographic disruption clearly occurred, there was little obvious disruption of production in the form of hesitations and the like. Therefore this seems more likely to be a phonologicallevel disruption.

\section{$\mathrm{C}_{\text {HALLENGING } \Rightarrow \text { ELK }}\left(\mathrm{U}_{\text {NIT }} 11\right)$}

This looks like a failed attempt to produce the correct phonology for the target word. Some of the correct phonological elements are present, with an incorrect $/ \mathrm{k} /$ instead of a $/ \triangleleft \diamond /$.

\section{Mixed semantic and phonological errors}

As mentioned above, most of the more obvious phonological errors occurred in combination with semantic ones. In explaining the derivation of some of them, I have had to make a number of educated guesses about intermediate representational states (these are indicated by a “?”).

$$
\mathrm{F}_{\text {LYNN }} \Rightarrow \mathrm{F}_{\text {ERGUS }}(?) \Rightarrow \mathrm{F}_{\text {ELGUS }}\left(\mathrm{U}_{\mathrm{NIT}} 8\right)
$$

The Irish surname Flynn is read as Felgus. This is not an Irish name, but is a close phonological neighbour to Fergus, which is a relatively common Irish first name. A possible explanation of this error is that a semantic paralexia is compounded by a corruption in phonology. 


\section{$\mathrm{A}_{\mathrm{CHONRY}} \Rightarrow$ THOMONGROSS RE RY (UNIT 9)}

Achonry is one of the lesser-known dioceses in Ireland. The name is not common in any context, and as such would have a very low frequency in the language. A relatively more well known diocese is Cork and Ross. Therefore a possible explanation of this error is that it represents a blend of the Thomas, Cork and Ross, and Achonry.

$$
\mathrm{S}_{\mathrm{LIGO}} \Rightarrow \mathrm{G}_{\mathrm{ALWAY}}(?) \Rightarrow \text { CALLWAY }\left(\mathrm{U}_{\mathrm{NIT}} 10\right)
$$

The broadcasting organisation for which RHR works, has a number of regional studios. Some of these are more frequently used in nationally broadcast programmes than others. The Sligo studio is one of those less frequently used. Sligo and Galway are geographically quite close, and transmissions from the Galway studio to Dublin would occur more frequently than from Sligo. Therefore, a possible explanation of this error is that it represents a combination of an intermediate semantic paralexia (Galway) which is then corrupted by the devoicing of its first consonant to yield callway.

\section{CHALLENGING $\Rightarrow$ CIRCULAR $(?) \Rightarrow$ KERKULAR $\left(U_{\text {NIT }} 11\right)$}

This is a similar pattern to the previous error. This time, the proposed intermediate paralexia is unrelated to the target. However, the phonological distortion is informative. In this case the "c" consonant is rendered as $/ \mathrm{k} /$ instead of $/ \mathrm{s} /$. Therefore, it is not a case of a single phonological feature being changed as with the previous error. This suggests that the locus of the disruption in phonology is more likely to be at the point where the phonological representation is mapped from the lexicon (phonological assembly), rather than during the phonetic realisation of this representation.

\section{Discussion}

Stepping back a little from the error analysis, it is possible to discern a number of trends. Early in the transcript we find errors that bear a strong resemblance to those found in studies of orthographic repetition blindness. This suggests that the seizure focus is possibly located more towards the posterior of the left temporal region, nearer to the visual areas. As the episode unfolds there is a gradual disruption of the lexical access system. Initially this disruption produces semantic paralexias, which then give way to neolgisms. In the latter part of the transcript the phonological representation of some of the words is corrupted. The best examples of this, however, tend to be in combination with paralexic errors. 
From the point of view of reading theory, the occurrence of something akin to repetition blindness is important, since it has not been identified in "natural" reading, although it is a robust phenomenon under the conditions of rapid serial visual presentation of text. The evidence from this episode suggests that the problem of maintaining multiple instances of the same letter type maybe an important component of skilled reading. In RHR's case, this skill component has been seriously disrupted. Therefore, it may be worthwhile exploring reading data, particularly of young readers, to see if there is evidence of its gradual emergence. It is also possible that some parameters of the reading process in adults might reflect this skill. For example, some of the variance in fixation durations may be accounted for by a process that prevents the disruption of lexical identification caused by the presence of multiple instances of the same letters or letter sequences in a fixation.

The temporal sequence of semantic paralexias followed by neologisms is support for the view that there are two separable stages in the lexicalisation process: retrieval of the lemma, followed by retrieval of the phonology (Harley, 1995). Failure to retrieve the lemma is evidenced by the semantic paralexias. Neologisms indicate a disruption of the phonology retrieval stage of this process. The fact that these occur in sequence rather than simultaneously, therefore, lends significant support to Harley's two-stage model.

\section{Acknowledgements}

I am very grateful to RHR for providing me with the tape and script of the programme, and his neurologist's report following the episode. Thanks to Máire Ní Chíosáin for help with phonetic transcription, and to Tatyana Nazir for pointing out the relevance of the repetition blindness literature.

\section{References}

Bavelier, D. \& Potter, M. (1992). Visual and phonological codes in repetition blindness. Journal of Experimental Psychology: Human Perception and Performance, 18, 134-147.

Chafe, W. (1994). Discourse consciousness and time: The flow and displacement of conscious experience in speaking and writing. Chicago, IL: University of Chicago Press. 
Cosslett, H.B. (1991). Read but not write "idea": Evidence for a third reading mechanism. Brain and Language, 40, 425-443.

Harley, T.A. (1995). The psychology of language: From data to theory. Howe, Sussex: Erlbaum (UK) Taylor Francis.

Harris, C.L., \& Morris, A.L. (submitted). Orthographic repetition blindness.

Hinton, G. E.\& Shallice, T. (1991). Lesioning an attractor network: Investigations of acquired dyslexia. Psychological Review, 98, 74-95.

Kanwisher, N. (1987). Repetition blindness: Type recognition without token individuation. Cognition, 27, 117-143.

Lesser, R. \& Milroy, L. (1993). Linguistics and aphasia: Psycholinguistic and pragmatic aspects. London, UK: Longman.

Marshall, K.E., \& Newcombe, F.(1980). The conceptual status of deep dyslexia: An historical perspective. In M. Coltheart, K.E. Patterson, \& J.C. Marshall (Eds.), Deep dyslexia (2 ${ }^{\text {nd }}$ Edition) (pp. 1-21). London: Routledge, Kegan, \& Paul.

McCarthy, R. \& Warrington, E.K. (1986). Phonological reading: Phenomena and paradoxes. Cortex, 22, 359-380.

Morton, J. \& Patterson, K.E. (1980). A new attempt at an interpretation, or an attempt at a new interpretation. In M. Coltheart, K.E. Patterson, \& J.C. Marshall (Eds.), Deep dyslexia $\left(2^{\text {nd }}\right.$ Edition) (pp. 91-118). London: Routledge, Kegan, \& Paul.

Patterson, K. E. \& Morton, J. (1985) From orthography to phonology: An attempt at an old interpretation. In K.E. Patterson, J.C. Marshall, \& M. Coltheart (Eds.) Surface dyslexia: Neuropsychological and cognitive studies of phonological reading. (pp. 335-359). Hove, UK: Erlbaum.

Plaut, D.C. \& Shallice, T. (1993). Deep dyslexia: A case study of connectionist neuropsychology. Cognitive Neuropsychology, 10, 377-500.

Schwarz, M., Saffran, E., \& Marin, O.S.M. (1980). The word order problem in agrammatism. 1 Comprehension. Brain and Language, 10, 249-262. 


\section{Table Captions}

Table 1

Transcript of RHR's dyslexic episode. Errors in bold are discussed in the text. 


\section{Figure Captions}

\section{Figure 1}

An information processing model of reading aloud. Ovals represent processing stages and rectangles represent temporary or permanent information stores. The shaded ovals represent three possible grapheme-to-phoneme processing routes as suggested from neuropsychological evidence. 
Table 1

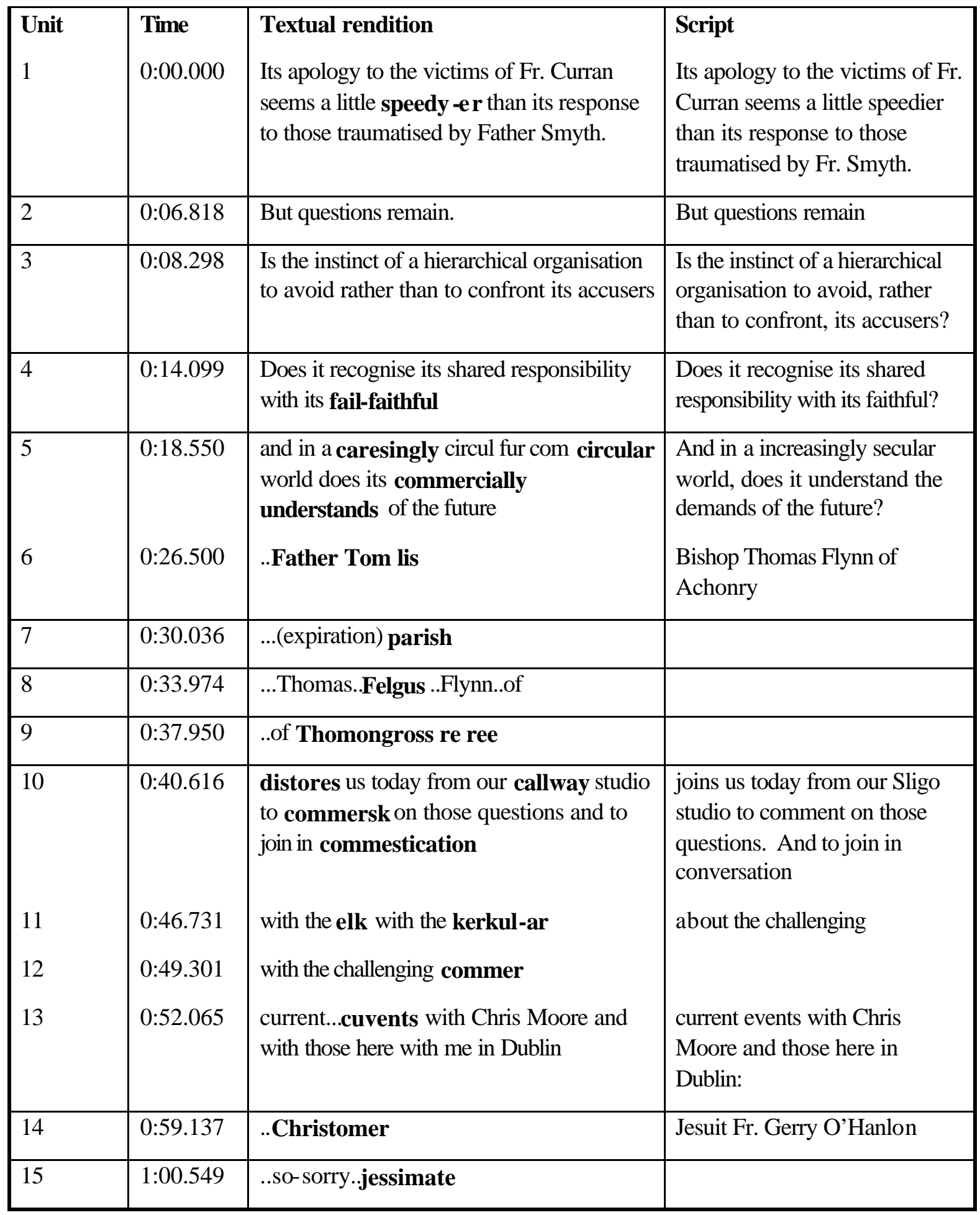




\section{Figure 1}

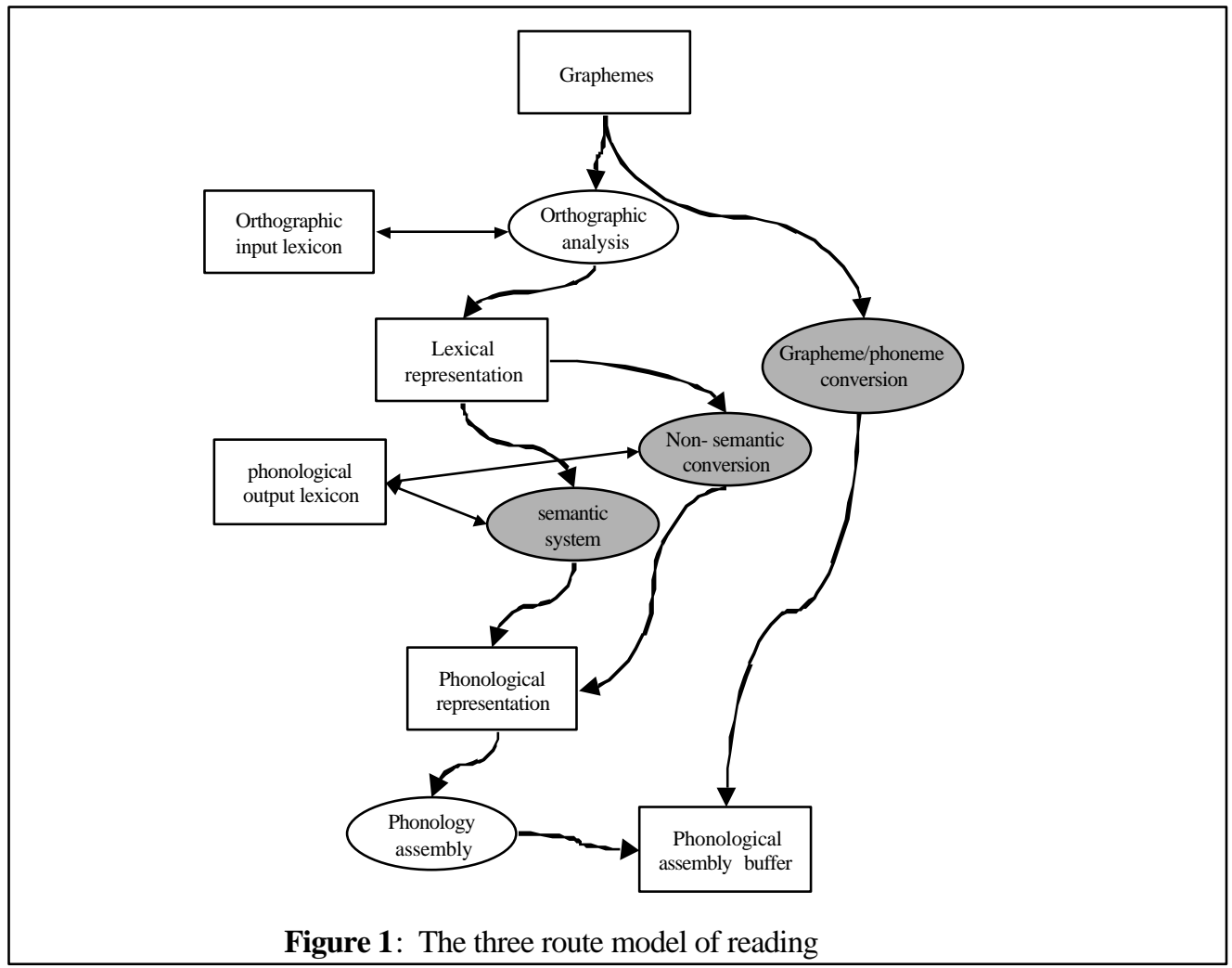

